\title{
$\mathbb{A}$ Economics Bulletin
}

\section{Volume 37, Issue 2}

\section{Firm-productivity and export under non-constant marginal costs}

\author{
Arijit Mukherjee \\ Nottingham University Business School
}

\begin{abstract}
Recent theoretical research shows that exporters are more productive than non-exporters. We show that this result holds almost trivially for the case of a constant marginal cost of production, as mainly assumed in the literature, but it may not hold true if the marginal cost is not constant. Our result provides a simple explanation for recent empirical evidence showing exporters can be less productive than non-exporters.
\end{abstract}

I would like to thank Professor Peter Neary and two anonymous referees of this journal for helpful comments and suggestions. The usual disclaimer applies.

Citation: Arijit Mukherjee, (2017) "Firm-productivity and export under non-constant marginal costs", Economics Bulletin, Volume 37, Issue 2, pages 911-917

Contact: Arijit Mukherjee - arijit.mukherjee@nottinghamac.uk.

Submitted: February 17, 2016. Published: May 01, 2017. 


\section{Introduction}

Melitz (2003) analyses the relationship between firm-productivity and export decision. Considering constant marginal costs of production, he shows that exporters are more productive than non-exporters. While this finding got support from many empirical studies (Greenaway and Kneller, 2007 and Bernard et al., 2012), several recent empirical papers suggest that exporters may be less productive than non-exporters (Dan, 2010, Hallak and Sivadasan, 2013, Wagner, 2013 and 2014).

Given this background, the purpose of this paper is two-fold. First, we provide a simple proof of Melitz's result and show that his result holds almost trivially for the case of constant marginal costs of production, as mainly assumed in the literature. Second, we show that his result may not hold under non-constant marginal costs of production. ${ }^{1}$

In what follows, we show in Subsection 2.1 that if the marginal cost of production is constant, 'a higher productive firm exports' follows immediately from a firm's standard investment decision, where investment occurs if the firm's operating profit is higher than the fixed cost. Since a lower marginal cost of production, which can be the outcome of a higher productivity of the firm, increases operating profit of the firm, a relatively higher productive firm will have higher incentive for investment.

In a recent paper, Mrazova and Neary (2013) show that the result of Melitz (2003), i.e., more productive firms export, holds even if the demand function is not CES, as considered in Melitz (2003). With constant marginal costs, they show that the result 'more productive firms export' holds irrespective of the demand function since it always satisfies the "supermodularity" 2 condition, where a higher productive firm gains more from export than a lower productive firm. Thus, Mrazova and Neary (2013) provide conditions more general than Melitz (2003) under which more productive firms export.

However, as mentioned above, empirical evidence does not always support the theoretical conclusion of Melitz (2003). Using data from Chinese firms, Lu (2010) shows that exporters may be less productive than non-exporters, and the paper explains that the differences in factor endowments and factor intensities are the reason for this departure from the prediction by Melitz (2003). The empirical analysis by Hallak and Sivadasan (2013) shows that small firms may export, and they explain this phenomenon in a theoretical model by considering two types of productivities - process productivity, which shows the ability to produce output using few variable inputs, and product productivity, which shows the ability to produce quality incurring low fixed outlays. The relationship between firm-productivity and product quality may then explain why many small firms become exporters. Using German data, Wagner (2013 and 2014) also show that exporters may be less productive. As per Wagner (2014), this may happen since low-productive exporters export high quality products.

We show in Subsection 2.2 that a lower productive firm may export in the presence of non-constant marginal costs of production. Thus, we provide a reason that is different from the existing reasons, such as the differences in factor endowments and factor intensities (Lu, 2010) and product quality (Hallak and Sivadasan, 2013 and Wagner, 2014). Our analysis suggests that while the supermodularity condition, mentioned in Mrazova and Neary (2013), is satisfied for any demand functions under a constant marginal cost, it may not be satisfied for nonconstant marginal costs.

\footnotetext{
${ }^{1}$ See, e.g., Ahn and McQuoid (2012), Vannoorenberghe (2012) and Senalp (2015) for some recent works on international trade with non-constant marginal costs. However, the focus of those papers is different from ours.

${ }^{2}$ The function $\pi(x, z)$ is supermodular in $(x, z)$ if $\pi\left(x_{1}, z_{1}\right)-\pi\left(x_{1}, z_{2}\right) \geq \pi\left(x_{2}, z_{1}\right)-\pi\left(x_{2}, z_{2}\right)$ when $x_{1} \geq x_{2}$ and $z_{1} \geq z_{2}$ (Mrazova and Neary, 2003).
} 
If the marginal cost is not constant, unlike the case of a constant marginal cost, the profits from domestic sell are affected by export. We first show in Subsection 2.2 the condition required for Melitz's result to hold under non-constant marginal costs and then provide an example in Subsection 2.2.1 to show that more productive firms can be non-exporters. The difference between the results under non-constant marginal cost of production and the constant marginal cost of production is attributed to the fact that export affects the concerned firm's profit from domestic sells under the former but not under the latter.

Our paper can be related to the literature on firm size and exporting. While the relationship between firm size and export propensity is considered to be positive (Bonaccorsi, 1992), the evidence on the relationship between firm size and export intensity, which is the ratio of exports to total sales, is inconclusive. There could be a positive (Wagner, 1995), negative (Patibandla, 1995) or no influence (Wolf and Pett, 2000) of firm size on export intensity. It follows from our example in Subsection 2.2.1 with linear demand functions and the same size of domestic and foreign markets, productivity has a non-monotonic relationship with the amount of export, but the ratio of export to total sales is independent of firm productivity.

The remainder of the paper is organised as follows. Section 2 describes the model and derives the results. Section 3 concludes.

\section{The model and the results}

\subsection{Constant marginal cost of production}

The purpose of this subsection is to provide a simple proof of Melitz's result, i.e., exporters are more productive than non-exporters.

Assume that there is a firm that sells its product in its domestic country and is deciding whether to export to a foreign country. If the firm exports to the foreign country, it needs to incur a fixed cost, $F$. For simplicity, we assume away any variable cost of exporting.

Assume that the total cost of the firm is $C=C(L, Q)$, where $L$ is the inverse of labourproductivity, $Q$ is the total output, $\frac{\partial C}{\partial L}>0, \frac{\partial C}{\partial Q}>0$ and $\frac{\partial^{2} C}{\partial Q^{2}}=0$. Hence, we consider here that the marginal cost of production is constant, as assumed in Melitz (2003). Further, as $L$ increases, i.e., productivity falls, it increases cost. We have $Q=q_{d}$ when the firm sells only in the domestic market and $Q=\left(q_{d}+q_{f}\right)$ when the firm sells in the domestic market and exports to the foreign market.

Assume that the demand functions in the domestic country and in the foreign country are $p_{d}\left(q_{d}\right)$ and $p_{f}\left(q_{f}\right)$ respectively.

If the firm sells only in the domestic market, it determines output to maximise $\left[p_{d}\left(q_{d}\right) q_{d}-C\left(L, q_{d}\right)\right]$. Denote the firm's equilibrium profit in this situation by $\pi^{x}(L)$.

If the firm sells in the domestic market and exports to the foreign market, it determines the domestic output, $q_{d}$, and the amount of export, $q_{f}$, to maximise $\left[p_{d}\left(q_{d}\right) q_{d}+p_{f}\left(q_{f}\right) q_{f}-C\left(L, q_{d}+q_{f}\right)-F\right]$. Since the firm's equilibrium domestic output is unaffected by the amount of export, the firm's equilibrium profit is given by $\pi^{x}(L)+\pi^{f}(L)-F$, where $\pi^{x}(L)$ is firm's profit from domestic sell and $\pi^{f}(L)-F$ is firm's net profit from export.

The firm sells in the domestic market and exports to the foreign market if $\pi^{x}(L)+\pi^{f}(L)-F>\pi^{x}(L)$ or $\pi^{f}(L)>F$. Using the envelope theorem, it is easy to show that 
if the firm's productivity increases, i.e., $L$ decreases, it increases $\pi^{f}(L)$. If $L$ is very high, $\pi^{f}(L) \rightarrow 0$, and if $\pi^{f}(L)>\mathrm{F}$ for some lower values of $L$, the firm exports if its productivity is higher than a threshold level, since that creates an operating profit that is higher than the fixed cost, $F$. In other words, a relatively higher productive firm sells in the domestic market and exports while a lower productive firm sells only in the domestic market, as shown by Melitz (2003).

The following proposition summarises the above discussion.

Proposition 1: If the total cost of a firm is $C=C(L, Q)$ with $\frac{\partial C}{\partial L}>0, \frac{\partial C}{\partial Q}>0$ and $\frac{\partial^{2} C}{\partial Q^{2}}=0$, the firm exports if $\pi^{f}(L)>F$, and since a higher productivity of the firm increases $\pi^{f}(L)$, the firm exports for productivities higher than a threshold productivity level.

\subsection{Non-constant marginal cost of production}

Now consider a situation where the firm faces a non-constant marginal cost of production. Assume that the total cost of the firm is $C=C(L, Q)$ with $\frac{\partial C}{\partial L}>0, \frac{\partial C}{\partial Q}>0$ and $\frac{\partial^{2} C}{\partial Q^{2}} \neq 0$.

If the firm sells only in the domestic market, it determines output to maximise $\left[p_{d}\left(q_{d}\right) q_{d}-C\left(L, q_{d}\right)\right]$ and its equilibrium profit is $\pi_{d}^{*}(L)$.

If the firm sells in the domestic market and exports to the foreign market, it determines the domestic output, $q_{d}$, and the amount of export, $q_{f}$, to maximise $\left[p_{d}\left(q_{d}\right) q_{d}+p_{f}\left(q_{f}\right) q_{f}-C\left(L, q_{d}+q_{f}\right)-F\right]$. In this situation, denote the firm's equilibrium profit by $\pi_{d f}^{*}=\tilde{\pi}_{d}^{*}+\tilde{\pi}_{f}^{*}$, where $\tilde{\pi}_{d}^{*}$ and $\tilde{\pi}_{f}^{*}$ are the profits from the domestic market and export respectively. Since we are considering non-constant marginal costs of production in this subsection, export by the firm affects its profit from domestic market. Hence, the firm sells in the domestic market and exports to the foreign market if $\tilde{\pi}_{d}^{*}+\tilde{\pi}_{f}^{*}-F>\pi_{d}^{*}$ or $\left(\tilde{\pi}_{d}^{*}-\pi_{d}^{*}\right)+\tilde{\pi}_{f}^{*} \equiv G>F$. Using the envelope theorem, we get that if the firm's productivity increases, i.e., $L$ decreases, it increases (decreases) $G$, i.e., $\frac{\partial G}{\partial L}<(>) 0$, if $\left.\frac{\partial C}{\partial L}\right|_{Q=q_{d}^{*}}<\left.(>) \frac{\partial C}{\partial L}\right|_{Q=\left(q_{d}^{*}+q_{f}^{*}\right)}$.

If $\frac{\partial G}{\partial L}>0$, it creates the possibility that a relatively lower productive firm can be the exporter. We now mention when a lower productive firm actually serves both the domestic and foreign markets but a relatively higher productive firm serves only the domestic market. Consider the range of $L$ over which $\left.\frac{\partial C}{\partial L}\right|_{Q=q_{d}^{*}}>\left.\frac{\partial C}{\partial L}\right|_{Q=\left(q_{d}^{*}+q_{f}^{*}\right)}$ or $\frac{\partial G}{\partial L}>0$. Now consider two values of productivities, say, $L_{1}$ and $L_{2}$, with $L_{1}<L_{2}$, which belong to the range of $L$ over which $\frac{\partial G}{\partial L}>0$. If the fixed cost of exporting, $F$, is such that $G\left(L_{1}\right)<F<G\left(L_{2}\right)$, the firm's net gain from selling in the domestic and foreign markets over selling only in the domestic market 
is positive for the labour coefficient $L_{2}$ (or productivity $\frac{1}{L_{2}}$ ) but it is negative for the labour coefficient $L_{1}$ (or productivity $\frac{1}{L_{1}}$ ). Hence, a firm with a lower productivity will sell in both the domestic and foreign markets but a firm with a relatively higher productivity will sell only in the domestic market.

$\left.\frac{\partial C}{\partial L}\right|_{Q=q_{d}^{*}}<\left.\frac{\partial C}{\partial L}\right|_{Q=\left(q_{d}^{*}+q_{f}^{*}\right)}$, and $F, L_{1}$ and $L_{2}$ are such that $L_{1}<L_{2}$ and $G\left(L_{2}\right)<F<G\left(L_{1}\right)$.

Hence, if the marginal cost is not constant, the result of Melitz (2003), i.e., exporters are more productive than non-exporters, does not hold if the labour productivities are such that $\left.\frac{\partial C}{\partial L}\right|_{Q=q_{d}^{*}}>\left.\frac{\partial C}{\partial L}\right|_{Q=\left(q_{d}^{*}+q_{f}^{*}\right)}$.

The above result suggests that if the marginal cost is not constant, a higher productivity increases (decreases) the incentive for export if the direct cost reduction due to a higher productivity is less (more) at the 'equilibrium domestic sell only' compared to the 'total equilibrium outputs under domestic sell and export'. If the direct effect of a higher productivity creates lower (higher) cost reduction at the 'equilibrium domestic sell only' compared to the 'total equilibrium outputs under domestic sell and export', it creates lower (higher) gain from 'domestic sell only' compared to 'domestic sell and export', thus increasing (decreasing) the incentive for export.

The following proposition follows from the above discussion.

Proposition 2: If the total cost of a firm is $C=C(L, Q)$ with $\frac{\partial C}{\partial L}>0, \frac{\partial C}{\partial Q}>0$ and $\frac{\partial^{2} C}{\partial Q^{2}} \neq 0, a$ higher (lower) productive firm can be the exporter if the labour productivities are such that $\left.\frac{\partial C}{\partial L}\right|_{Q=q_{d}^{*}}<\left.(>) \frac{\partial C}{\partial L}\right|_{Q=\left(q_{d}^{*}+q_{f}^{*}\right)}$.

\subsubsection{An example}

Now consider an example with a specific cost function. Assume that the cost function is $C(L, Q)=10 L^{2} Q-L^{3} Q^{2}$. This cost function has the following property: $\frac{\partial C}{\partial Q}=2 L^{2}(5-L Q)>0$ for $L Q<5, \frac{\partial^{2} C}{\partial Q^{2}}=-2 L^{3}<0$ and $\frac{\partial C}{\partial L}>0$ for $3 L<20$. Hence, we consider the parameter values such that $L Q<5$ and $3 L<20$. We consider in the following analysis that $0<L<.5$ and the domestic and foreign demand functions are respectively $P_{d}=10-q_{d}$ and $P_{f}=10-q_{f}$.

Standard calculation gives the following equilibrium values. If the firm sells only in the domestic market, its equilibrium output and profit are respectively $q_{d}^{*}=\frac{10\left(1-L^{2}\right)}{2\left(1-L^{3}\right)}$ and $\pi_{d}^{*}=\frac{\left(10-10 L^{2}\right)^{2}}{4\left(1-L^{3}\right)}$. If the firm sells in the domestic market and exports, its equilibrium outputs 
and profit are respectively $q_{d}^{*}=q_{f}^{*}=\frac{5\left(1-L^{2}\right)}{\left(1-2 L^{3}\right)}$ and $\pi_{d f}^{*}=\frac{50\left(1-L^{2}\right)^{2}}{\left(1-2 L^{3}\right)}-F$. It is easy to check that the equilibrium values satisfy the constraint $L Q<5$ and $3 L<20$ for $0<L<.5$.

Comparing $\pi_{d}^{*}$ and $\pi_{d f}^{*}$, we get that the firm exports if $F<G \equiv \frac{50\left(1-L^{2}\right)^{2}}{\left(1-2 L^{3}\right)}-\frac{\left(10-10 L^{2}\right)^{2}}{4\left(1-L^{3}\right)}=\frac{25(1-L)(1+L)^{2}}{\left(1+L+L^{2}\right)\left(1-2 L^{3}\right)} . \quad$ We $\quad$ get $\quad$ that $\frac{\partial G}{\partial L}=\frac{25 L(1+L)\left[\mathrm{L}+5 \mathrm{~L}^{2}-4(1-L)\left(1-2 L^{3}-\mathrm{L}^{4}\right)\right]}{\left(1+L+L^{2}\right)^{2}\left(1-2 L^{3}\right)^{2}} . \quad$ Hence, $\quad \frac{\partial G}{\partial L}>(<) 0 \quad$ for $\left[\mathrm{L}+5 \mathrm{~L}^{2}-4(1-L)\left(1-2 L^{3}-\mathrm{L}^{4}\right)\right]>(<) 0$. We get that $\left[\mathrm{L}+5 \mathrm{~L}^{2}-4(1-L)\left(1-2 L^{3}-\mathrm{L}^{4}\right)\right]<0$ at $L=0$ but $\left[\mathrm{L}+5 \mathrm{~L}^{2}-4(1-L)\left(1-2 L^{3}-\mathrm{L}^{4}\right)\right]>0$ at $L=.5$, implying that $\frac{\partial G}{\partial L}>0$ for $L$ close to .5 .

Plotting $\frac{\partial G}{\partial L}$ with respect to $L \in[0, .5]$, we get the following diagram (Figure 1), which shows that a higher productivity of the firm decreases the incentive for export (i.e., $\frac{\partial G}{\partial L}>0$ ) for $L$ close to .5 but it increases the incentive for export (i.e., $\frac{\partial G}{\partial L}<0$ ) otherwise.

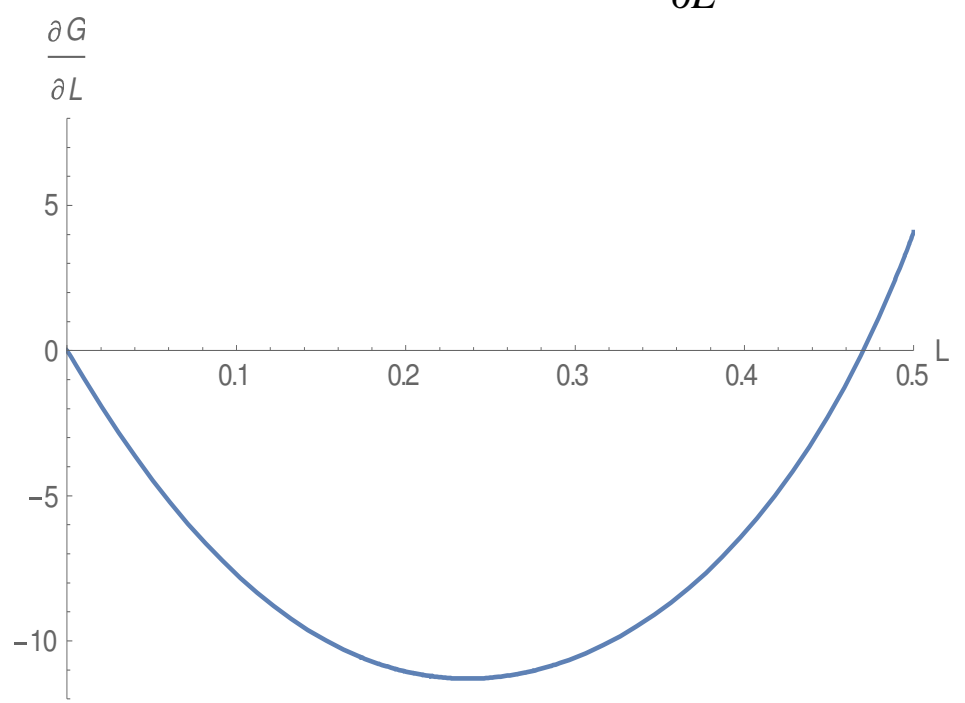

Figure 1: The relationship between $\frac{\partial G}{\partial L}$ and $L$

One can find a similar result by comparing $\left.\frac{\partial C}{\partial L}\right|_{Q=q_{d}^{*}}$ and $\left.\frac{\partial C}{\partial L}\right|_{Q=\left(q_{d}^{*}+q_{f}^{*}\right)}$. We have $\frac{\partial C}{\partial L}=2 L^{2}(5-L Q) . \quad$ Hence, $\left.\quad \frac{\partial C}{\partial L}\right|_{Q=q_{d}^{*}}=\frac{25 L(1+L)\left(4+L+L^{2}\right)}{\left(1+L+L^{2}\right)^{2}} \quad$ and
$\left.\frac{\partial C}{\partial L}\right|_{Q=\left(q_{d}^{*}+q_{f}^{*}\right)}=\frac{100 L\left(1-L^{2}\right)\left(2-3 L-L^{3}\right)}{\left(1-2 L^{3}\right)^{2}}$. Denoting $\left(\left.\frac{\partial C}{\partial L}\right|_{Q=q_{d}^{*}}-\left.\frac{\partial C}{\partial L}\right|_{Q=\left(q_{d}^{*}+q_{f}^{*}\right)}\right)=\frac{\Delta C}{\Delta L}$ and plotting 
$\frac{\Delta C}{\Delta L}$ with respect to $L \in[0, .5]$, we get the following diagram (Figure 2), which is like Figure 1 .

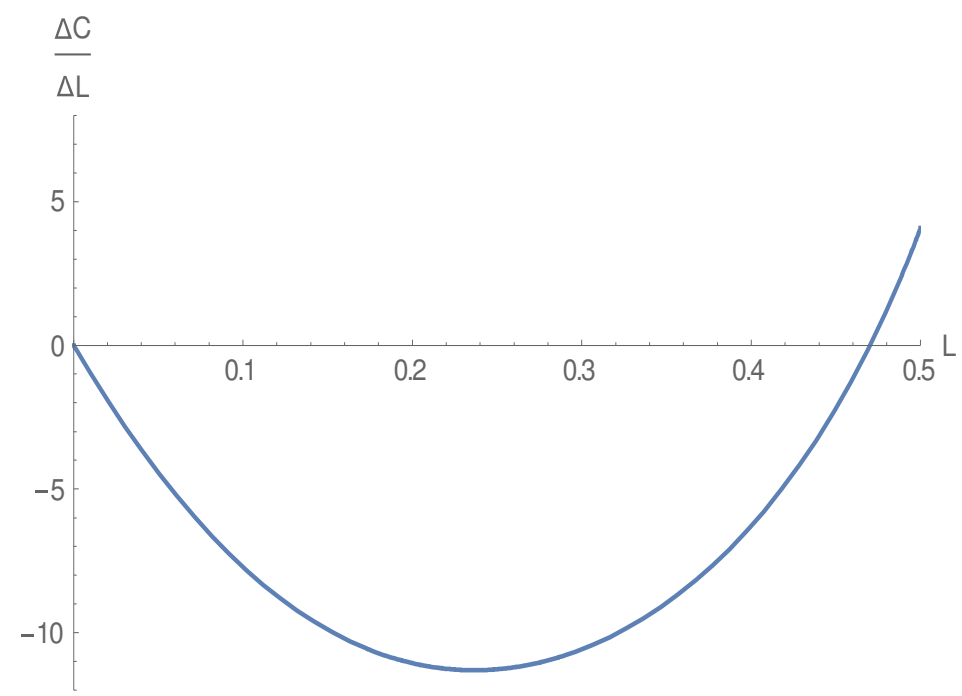

Figure 2: The relationship between $\frac{\Delta C}{\Delta L}$ and $L$

The above example and the corresponding diagram show that, since there is a range of $L$ over which $\frac{\partial G}{\partial L}>0$, there is a possibility that a lower productive firm serves both the domestic and foreign markets but a relatively higher productive firm serves only the domestic market. Now we want to show when this actually happens. Let's consider the following parameter values: $F=21.38, L=.47$ and $L=.49$. We get that $G(.47)=21.3704$ and $G(.49)=21.3953$, implying that $G(.47)<F<G(.49)$. Hence, a firm with a labour coefficient $L=.49$ serves both the foreign and domestic markets but a firm with a labour coefficient $L=.47$ serves only the domestic market, showing that a relatively lower productive firm can be the exporter.

\section{Conclusion}

We show that the result showing exporters are more productive than non-exporters holds almost trivially for the case of a constant marginal cost of production, as mainly assumed in the literature. However, this result may not hold if the marginal cost is not constant. Our result provides a simple explanation for recent empirical studies showing exporters may be less productive than non-exporters.

\section{References}

Ahn, J. and A.F. McQuoid (2012) "Capacity constrained exporters: micro evidence and macro implications" Mimeo, Florida International University, USA.

Bernard, A.B., J.B. Jensen, S.J. Redding and P.K. Schott (2012) "The empirics of firm heterogeneity and international trade" Annual Review of Economics 4, 283-313.

Bonaccorsi, A. (1992) "On the relationship between firm size and ex-port intensity" Journal of International Business Studies 23, 605-635. 
Greenaway, D. and R. Kneller (2007) "Firm heterogeneity, exporting and foreign direct investment" Economic Journal 117, F134-F161.

Hallak, J.C. and J. Sivadasan (2013) "Product and process productivity: Implications for quality choice and conditional exporter premia" Journal of International Economics 91, 53-67.

Lu, D. (2010) "Exceptional exporter performance? Evidence from Chinese manufacturing firms" Working paper, University of Chicago.

Mrazova, M. and P.J. Neary (2013) "Selection effects with heterogeneous firms" CEPR Discussion Paper No. DP9288.

Melitz, M.J. (2003) "The impact of trade on intra-industry reallocations and aggregate industry productivity" Econometrica 17, 1692-1725.

Patibandla, M. (1995) "Firm size and export behaviour: an Indian case study" Journal of Development Studies 31, 868-882.

Senalp, U. (2015) "Essays on firm heterogeneity and international trade" PhD thesis, Loughborough University, UK.

Vannoorenberghe, G. (2012) "Firm-level volatility and exports" Journal of International Economics 86, 57-67.

Wagner, J. (1995) "Exports, firm size, and firm dynamics" Small Business Economics 7, 2939.

Wagner, J. (2013) "Are low-productive exporters marginal exporters? evidence from Germany" Economics Bulletin 33, 467-481.

Wagner, J. (2014) "Low-productive exporters are high-quality exporters: evidence from Germany" Economics Bulletin 34, 745-756.

Wolf, J.A. and T.L. Pett (2000) "Internationalization of small firms: an examination of export competitive patterns, firm size, and export performance" Journal of Small Business Management 38, 34-47. 